\title{
Research on the Tea Culture of Yuan Dynasty
}

\author{
Hongyun $\mathrm{Wu}^{1, \mathrm{a}}$, Jianchun $\mathrm{Shao}^{2, \mathrm{~b}, *}$ \\ ${ }^{1}$ College of Art, Jingdezhen University, Jiangxi,333400, China \\ ${ }^{2}$ College of Humanities, Jingdezhen University, Jiangxi,333400, China \\ a410494445@qq.com,bjdzsjc@163.com \\ *corresponding author
}

\begin{abstract}
The content of tea culture in the Yuan Dynasty was rich, the activities of tea were diversified, and Han and Tibetan nationalities had cultural exchanges towards integration. People in the Yuan Dynasty not only inherited the old customs of Tea-boiling and Tea-stippling in the Tang and Song Dynasties but also created a simple brewing method of loose tea and scented tea, they opened a new style of tea drinking in the Ming and Qing dynasties. Yuan Opera, tea poetry, tea painting and other literature and art described the prosperity of the tea events in the Yuan Dynasty. The tea ceremonies in the Yuan Dynasty enjoyed both refined and popular tastes, connecting the past and the future, should occupy a place in the history of Chinese tea industry development.
\end{abstract}

Keywords: Tea culture, Scented tea, Loose tea, Brewing method, Cultural exchange

\section{INTRODUCTION}

China is the origin of tea, tea culture with a long history is an important part of China's excellent traditional culture. The origin of Chinese tea drinking can be traced back to the ancient times of Shennong. According to the Shennong Ben Cao Jing, tea had the function of detoxification. Tea expert $\mathrm{Lu} \mathrm{Yu}$ in Tang Dynasty believed that tea originated in Shennong. During the Wei and Jin Dynasties, tea drinking was mainly popular in the south, and the northerners believed that tea drinking was suffering, not enjoyment. In the middle and late Tang Dynasty, tea ceremony was popular. Under the influence of Zen Culture, tea drinking began to spread all over the north and south of the Yangtze River and became a matter of daily life. Since the Song Dynasty, tea had been one of the most important seven necessities, and the tea ceremony had also become an elegant enjoyment of spiritual life. The Literati and Literati were keen to drink tea. Although the Yuan Dynasty was a time when the minority came to Central Plain, the tea drinking custom continued the development of the Tang and Song dynasties, instead of ending abruptly due to the change of dynasties, tea affairs continued, refined and popular, with multi-ethnic cultural exchanges and integration, becoming an important link in the history of Chinese tea from the Tang and Song Dynasties to the Ming and Qing Dynasties.

\section{METHODS OF DRINKING TEA}

Mongolian as a nomadic people, as cheese, meat as the main food, usually needed to drink tea to help digestion, in addition to the well-developed Chinese and foreign transportation, the introduction of tea, so that the tea culture of the Yuan Dynasty took on a colorful situation. Although the production and drinking of tea in the Yuan Dynasty basically followed the Song system, there were some unprecedented new scenes in the way and cultural content of tea drinking. First of all, there were great changes in the tea drinking custom in Yuan Dynasty. The upper classes followed the Song Dynasty's practice of Matcha tea. The tea needed by the royal family was still mainly made of Dragon, ball and Phoenix cakes, which were still produced and served by the Gong Bakeries. However, the Royal Family preferred the tea with flavouring, which could be added to the tea when it was cooked. Secondly, the custom of drinking tea formed with fragrant flowers, fruits and others. It was a characteristic of tea culture of Yuan Dynasty that tea was made by absorbing the fragrance of flowers and fruits by using the peculiar smell of tea. The tea of the Yuan Dynasty was mainly made up of cake tea and loose tea, the way of drinking tea in the Yuan Dynasty had both inheritance and innovation. Ye Ziqi, a scholar from the late Yuan Dynasty and the early Ming Dynasty, wrote that imperial tea was made in Jianning, Fujian. People in Jiangxi usually drank loose 
tea. On the one hand, people of the Yuan Dynasty still used the decocting method of the predecessors, stippling tea or fighting tea, which was more complicated and spread among the court nobles, bureaucrats and officials. On the other hand, people began to make tea by the simple way of brewing tea, cutting down the complexity and simplifying it, instant drink, which opened a new trend of drinking tea in the Ming and Qing Dynasties. Agronomist Wang Zhen recorded that there were three kinds of tea, known as cake tea, loose tea and wax tea. Loose tea was easy to make and cheap to sell, and that was mainly popular among the common people, While wax tea is the most precious, usually used in the court[1]. The loose tea overpowered the round cake tea and became one kind of popular tea product at that time. As the scholar Chen Xuxia said, this is a characteristic of the tea culture of the Yuan Dynasty[2].

Tea Drinking in the Yuan Dynasty had some differences from that in the Tang and Song Dynasties. People of Tang Dynasty drank tea, or more precisely, they ate tea. The tea was often mixed with spices such as ginger and dates, and boiled into porridge to be mixed with food. According to the book of Tea, with scallions, ginger, dates, orange peel, dogwood, mint, etc., boiled many times, even the tea Saint Lu Yu opposed, who thought this way was s not appropriate, but that had formed a climate, people liked it very much, this may have something to do with Zen tea. Monks in the Tang Dynasty like to drink tea. Because of no lunch after noon, they can only drink tea to alleviate hunger. The famous painting of Xiao Yi Zhuan lan pavilion in the Tang Dynasty is a tea painting in which the monks treated their guests with tea. People began Tea Fights in the Song Dynasty instead of boiling tea. They poured boiling water directly into the cup with a soup bottle and stirred it to whisk it, they paid more attention to the tea color, no more seasoning. People in the Song Dynasty were fond of fighting over tea, whether it was Emperor Huizong of Song's painting Wen Hui Tu, or Liu Songnian's tea painting Nian Cha Tu or Ming Yuan Gambling Market Tu. People in the Yuan Dynasty began to innovate the direct brewing method of tea, because it was simple and easy to do, and finally formed the mainstream of Ming and Qing Dynasties, and had affected so far.

Of course, People in the Yuan Dynasty also retained the style of the Tang and Song Dynasties, mainly inheriting the tea-stippling method of the Song Dynasty. For example, the Tomb Mural of the tea ceremony, unearthed in Chifeng, Inner Mongolia in 1987, vividly recreated the tea-stippling scene in the Yuan Dynasty, and the tomb mural of the Taoist priest excavated in 1958 from the tomb of Feng Daozhen in Datong,Shanxi in the Yuan Dynasty,then reproduced that people in the garden small scenery serviced guest with tea. Zhao Mengfu painted the Tea Fight Tu. At the same time, some tea was also mixed with pine nuts, for people to chew, with a style of Tang Dynasty heritage[3]. In addition, the Yuan Dynasty also formed a distinctive Mongolian national characteristics of tea drinking method. And butter tea mixed with orchid incense was delicious and easy to make. These were obviously the result of cultural exchange of Han and Mongolian diet[4]. The Yuan Dynasty absorbed some of the original ways of drinking tea in Central Plain, combined with the cultural characteristics of the nation, and formed a tea drinking with Mongolian characteristics. This kind of tea could be drunk, but also edible, not only by the Mongolian nobles welcome, but also spread to the Han and other ethnic groups, greatly enriched and developed the tea culture of the Yuan Dynasty. Although the Yuan Dynasty was ruled by ethnic minorities, the cultural heritage of the Chinese nation and the way of tea making was still retained among some literati, and the snow sweeping and cooking tea in the mind of the literati elegant things was still popular.

\section{TEA CEREMONIES AND TEA CULTURE}

After the rulers of Mongolia came to Central Plain, they were influenced by the profound farming culture and also brought fresh nomadic culture. Fang Xiaoru, a scholar at the beginning of the Ming Dynasty, said that after the death of the Song Dynasty and the reign of the Yuan Dynasty in China for more than 80 years, the language of the Chinese people, their food, their utensils and their formal clothes were changed into foreign ones. The emperor of the Yuan Dynasty had some knowledge of the tea culture in Central Plain and was able to accept it. The spring called Jinsha had dried up in the Song Dynasty, and it resumed spraying in the Yuan Dynasty, so Guzhu tea production was supplied. So Kublai Khan rewarded it.In the Sixth Year of Dade, Yuan Chengzong established a Royal Tea Garden in Fujian and supervised the making of Wuyi tribute tea. In the Sixth year of Dade, Yuan Chengzong established a royal tea garden in Fujian and supervised the making of Wuyi tribute tea. In the year of Zhida, Külüg Khan, Emperor Wuzong of Yuan moved willow forest hunting, passing Zou shop thirsty, he thought of drinking tea and ordered to boil tea. Later in the Yuan Dynasty, the emperor was more sinicized and liked to drink tea. He was accompanied by a lady-in-waiting who specialized in serving tea. The Lady of Goryeo, Qi, became the empress because she was good at serving tea[5]. According to the literature, the Yuan court was rich in tea, there were medlar tea, yumo tea, Jinzi tea, Fandianshuai tea, purple bamboo shoots sparrow tea, nuxue er, Xixiang tea, Sichuan tea, Rattan tea, swallow tail swallow, children tea, warm mulberry tea, clear Tea, fried tea, Langao tea, Jiantang tea, fragrant tea. In addition, the palace menu included Chinese catered rice, Hui people catered rice, Indian catered rice, Uyghur, Uyghur catered rice and so on, indicating that tea had entered the daily life of the supreme ruler. 
People in the Yuan Dynasty generally liked to drink tea. Tea was not only an indispensable part of daily life, one of seven necessities, but also a high-level enjoyment of spiritual and cultural life, Life and death, marriage and funeral marry were always accompanied by tea, tea had become a household necessity, tea had become more routine, etiquette, poetic. Tea poems, tea paintings, Yuan opera and other literary and artistic works of the Yuan Dynasty all contained a large number of descriptions of tea events[6]. Folk people in the Yuan Dynasty were popular with boiling water to drink. tea was often accompanied with food, wine, fruit and so on, which could be seen in many poems. For example, "If a guest comes, he should be treated with tea." "When a guest comes to the house, you can serve tea instead of wine." "Can laugh Nantang old farmer's home, guests only cooking tea without wine." "When you come, you will recite poems. When you come, you will drink tea." "Tea welcomes visitors from the three islands, and soup delivers guests from the five lakes." "My house is near the lake. The handsome man comes to my house for tea." When you get along with your friends, tea is often used to entertain the guests. This had become a kind of etiquette in Yuan Dynasty. As the tea custom, there was the ceremony of tea betrothal. Tea drinking had a long history in China. It was said that before $280 \mathrm{AD}$, there was a small country in the south of China called $\mathrm{Wu}$. When the king entertained his ministers, he liked to get them drunk with wine. One of them, a minister named Wei Zhao, could not hold his liquor, so the king asked him to substitute tea for wine. From then on, the literati began to receive guests with tea. It was a Chinese custom to entertain guests with tea. When the guest comes in, the host immediately sent a cup of Fragrant Tea, drinking tea while talking, the atmosphere was relaxed and happy. To the Tang Dynasty, drinking tea had become a habit of people. It was also said to be associated with Buddhism. Around 713-741 AD, when the monks in the temple were sitting in meditation for a long time, they liked to doze off and eat, so the old monk figured out a way to make them drink tea to excite their nerves, the idea spread everywhere. Tea has become a unique cultural phenomenon in China. People Take tea tasting as an art. Since ancient times, all over China have different forms of teahouses, Where people drink tea, eat snacks, enjoy cultural performances, which can be said to rest, entertainment, kill two birds with one stone. In the south of China, there are not only teahouses, but also a kind of tea house. This kind of tea house is usually set up in a beautiful place. In some places, when drinking tea, they also like to put some condiments into the tea. For example, in some places in Hunan Province in the south, ginger salt tea is often used to serve guests. There are not only tea leaves, but also salt, Ginger, fried soybeans and sesame seeds. When drinking tea, you can shake it while drinking it, finally, the beans, sesame, ginger and tea into the mouth, slowly chewing out the flavor, so many places also known as Tea. The way of making tea also has its own habits, in eastern China people like to use a large teapot, when guests enter the door, put the tea leaves in the pot, poured boiling water, after the tea is ready, then poured into the cup. Some places, such as Zhangzhou in eastern China's Fujian Province, Kung Fu tea, not only unique tea sets, but also very special brewing method, forming a unique tea ceremony art. In Beijing, when the host serves tea, the guest should immediately stand up, take the cup with both hands and say "Thank you". In Guangdong and Guangxi in the south, after tea is served, the owner should tap the table top three times gently with the fingers of his right hand after bending to express his gratitude. In other areas, guests want to continue drinking tea, tea should be left in the cup, and the host will continue to add tea, if all the tea will be poured, the host thinks you no longer drink, also do not give you tea. In particular, tea culture has penetrated into the civilian class since the Song Dynasty. The most prominent manifestation is the widespread rise of teahouses in large and small cities. Various tea cultures have not only continued and developed in the courts, religions, Literati and officialdom, the spirit of tea culture is further rooted in the broad masses of the people, scholars, farmers, industry and commerce have tea as a gathering of friends, the media of interpersonal communication. There are abundant Tea folk customs in different regions and nationalities. Although the short history of the Yuan Dynasty could not show the glory of culture, but tea-learning and tea culture since the Tang and Song dynasties still continued the excellent tradition, and the development of innovation. Mongols, which had no chance with tea, gradually accepted the influence of tea culture after entering Central Plain. Mongolian aristocrats liked tea. tea production was an important stimulus and promotion. The Yuan Dynasty began to appear loose tea. Cake tea was mainly used by the royal court. the folk were mainly loose tea. As a result of the popularity of loose tea, tea processing began to appear fried green technology, the processing of scented tea also form a complete system. Chinese and Mongolian food culture exchanges, but also formed a Mongolian characteristics of tea drinking, tea began to appear, with boiling water directly brewed tea. All these laid a foundation for the rise of roasted green tea in the Ming and Qing Dynasties.

People in the Yuan Dynasty also liked to give women names of tea. People in the Jin and Yuan dynasties called women Tea. For example, "Into the home of a wealthy Jurchen people family, his petite 13-year-old daughter named Cha-cha." "I'm from Jurchen people. My name is Cha-cha." Because people engaged in the tea management and the sale, the Yuan Dynasty literature also had molded a batch of tea managers, tea doctor, tea Sanpo, tea merchant named Feng Kui, Liu Yilang, Guo Maer, tea clerk and so on[7]. 
Such as the tea master, "The Golden Goblet was full of lamb wine, not like the pan-jade ou of the Lingya, which was famous all over Yueyang Tower." Such as profiteers named Feng Kui, "But for three thousand tea yin, married Feng Kui", "Double gradually poor, Feng Kui rich", "Selling tea boat, buy life money. Feng Kui married a beautiful woman and fulfilled his wish.

In the Yuan Dynasty, the rulers held Buddhism and Taoism in high esteem, but they had no respect for the intellectuals. The imperial examination was suspended for a long time. The official career was also very dangerous. For example, Zhang Kejiu, a famous literary man, retired to the West Lake to amuse himself with tea and wine, wrote Hanerling Chunsi to express his ambition; Qiao Ji lamented that his ambition was difficult to fulfill, but he wrote happily that "Everything should be done from him". The story of tea described in the poetry of Yuan Dynasty has become a literary and artistic form of expression. The imperial examination was marginalized, and the scholar's career was hopeless. Even if the opportunity to enter officialdom, but high-ranking officials of the court must be of Mongolian origin. Non-Mongolians were hard to promote. Officials at the middle and lower levels were often selected from transactional staff, officials were corrupt, the bureaucracy was dark, and no way to serve the country. That resulted in more literati and officialdom had the idea of seclusion, they turned to the embrace of Zen and Taoism. They participated in Zen and Taoism, pursuing Zen tea blindly, harmony between man and nature, integration of the three religions, and the meaning of Zen thought became stronger in the tea ceremony, such as Taoist priest invited to sit, fairy child serviced for tea;[8]. The Taoist priest was flying over Longtan on a crane, and his boy was busy making tea. The picture of boiled tea was a landscape painting by the famous artist Wang Meng in the Yuan Dynasty. The painting depicted Wang Meng's reclusive landscape in his later years, created during his "Reclusive landscape" period.

\section{CONCLUSION}

The rulers of the Yuan Dynasty attached great importance to agriculture after they came to Central Plain. The Emperor of the Yuan Dynasty not only accepted the tea drinking custom of the Han region, but also injected the features of the customs of Mongols. People of the Yuan Dynasty continued the method of brewing tea in Tang and Song Dynasties, They made an innovation of a more simple way of brewing, loose tea began to be popular, and eventually developed into the mainstream of the Ming and Qing Dynasties. Because of the weak imperial examination, the reclusive thought of the literati and officialdom in the Yuan Dynasty became more intense. Some colorful tea activities in the Yuan Dynasty were vividly described by Yuan Opera, tea poetry, tea painting and other literature and art, leaving precious spiritual wealth for future generations. The tea ceremonies in the Yuan Dynasty enjoyed both refined and popular tastes, connecting the past and the future. That was an indispensable link in the history of Chinese tea.

\section{ACKNOWLEDGMENTS}

This article is a phased achievement of the research projects of Humanities and Social Sciences in Colleges and Universities of Jiangxi Province, on background of Chinese figure paintings in Jin, Tang, Song, and Yuan Dynasties, Project No.YS1409; on the development of tea service in Jingdezhen during the Tang, Song and Yuan dynasties, Project No.KG1401.

\section{REFERENCES}

[1] Wang Zhen.(1956). The Book of Agriculture. Zhonghua book company, vol.10,pp.226-227.

[2] Chen Xuxia.(2008).Tea Customs, tea products, tea art: Tea Culture seen in Yuan Opera, Agricultural archaeology,No.2,pp.68.

[3] Wang Zhen.(1956). The Book of Agriculture. Zhonghua book company, vol.10,pp.273.

[4] Wang Lixia.(2011).tea culture in the Yuan Dynasty: The embodiment of multi-ethnic cultural integration, Tea, No.5,pp21-22.

[5] Chen Gaohua et al.(2009). Cultural history of Yuan Dynasty. Guangdong education press,pp.260-262.

[6] Chen Xuxia.(2008).Tea Customs, tea products, tea art: Tea Culture seen in Yuan Opera, Agricultural archaeology,No.2,pp.70.

[7] Yang Zengwen.(2006).A history of Zen Buddhism in the Song and Yuan Dynasties, Chinese Social Sciences Press,pp. 285.

[8] Wang Lixia.(2010).The reclusive feelings of tea culture in Yuan Dynasty -- Taking poetry of the Yuan Dynasty as the center, Agricultural archaeology, No.5,pp.35. 